\title{
Real-World Database Examining the Association between Sjögren's Syndrome and Chronic Rhinosinusitis
}

\author{
Geng-He Chang ${ }^{1,+}{ }^{+}$Yu-Cheng Chen ${ }^{2,+}{ }^{+}$Ko-Ming Lin ${ }^{3,4}$, Yao-Hsu Yang ${ }^{5,6,7}$, Chia-Yen Liu ${ }^{5}$, \\ Meng-Hung $\operatorname{Lin}^{5}{ }^{(\mathbb{D}}$, Ching-Yuan $\mathrm{Wu}^{6,7}$, Cheng-Ming Hsu ${ }^{1,7}$ and Ming-Shao Tsai ${ }^{1,5, * \mathbb{C}}$ \\ 1 Department of Otolaryngology - Head and Neck Surgery, Chiayi Chang Gung Memorial Hospital, \\ Chiayi 613, Taiwan; genghechang@gmail.com (G.-H.C.); scm00031@gmail.com (C.-M.H.) \\ 2 Department of General Medicine, Chiayi Chang Gung Memorial Hospital, Chiayi 613, Taiwan; \\ u9702036@cmu.edu.tw \\ 3 Department of Rheumatology, Chiayi Chang Gung Memorial Hospital, Chiayi 613, Taiwan; \\ koming@cgmh.org.tw \\ 4 College of Medicine, Chang Gung University, Taoyuan 333, Taiwan \\ 5 Health Information and Epidemiology Laboratory of Chang Gung Memorial Hospital, Chiayi 613, Taiwan; \\ r95841012@ntu.edu.tw (Y.-H.Y.); qchiayen@gmail.com (C.-Y.L.); mattlin@cgmh.org.tw (M.-H.L.) \\ 6 Department of Traditional Chinese Medicine, Chiayi Chang Gung Memorial Hospital, Chiayi 613, Taiwan; \\ smbepigwu77@gmail.com \\ 7 School of Traditional Chinese Medicine, College of Medicine, Chang Gung University, Taoyuan 333, Taiwan \\ * Correspondence: b87401061@cgmh.org.tw \\ + The author contributed equally to this work.
}

Received: 22 December 2018; Accepted: 26 January 2019; Published: 30 January 2019

\begin{abstract}
Objective: To investigate the risk of chronic rhinosinusitis (CRS) among patients with Sjögren's syndrome (SS). Method: A total of 18,723 patients diagnosed with SS between 1997 and 2011 were retrospectively analyzed. Moreover, 59,568 patients without SS were matched to patients with SS at a 1:4 ratio on the basis of sex, age, urbanization level, income level, and the comorbidities of rhinitis and nasal sepal deviation. Patients were followed up until death or the end of the study period (31 December, 2013). The primary outcome was the occurrence of CRS. Results: The cumulative incidence of CRS was significantly higher in patients with SS than in those without SS $(p<0.001)$. The adjusted Cox proportional hazard model showed that patients with SS had a significantly higher incidence of CRS (hazard ratio, 2.51; 95\% confidence interval, 2.22-2.84; $p<0.001$ ). Sensitivity and subgroup analyses demonstrated SS was an independent risk factor for CRS. The dosage of intranasal corticosteroid spray used was not different between the SS and non-SS groups. Fewer patients with CRS in the SS group underwent sinus surgery $(82 / 407(20.2 \%))$ than those in the non-SS group $(179 / 667(26.8 \%))$ and this finding was statistically significant $(p=0.013)$. The number of operations did not differ significantly between patients with CRS in the SS and non-SS groups. Conclusions: SS is an independent risk factor for CRS. Our study extends the disease spectrum and prompts physicians to be aware of potential CRS occurrence after SS.
\end{abstract}

Keywords: Sjögren's syndrome; sicca; autoimmune diseases; sinusitis

\section{Introduction}

Chronic rhinosinusitis (CRS), one of the most common diseases globally, continues to have a negative impact on patients' quality of life [1]. Even with improvements in medications and surgical techniques in the past few decades, CRS still has a high prevalence of $2-16 \%$ worldwide [2]. A patient 
with CRS is estimated to lose approximately $\$ 200$ U.S. dollars for every missed working day, and CRS results in an enormous health burden in many countries [2].

Sjögren's syndrome (SS) is a chronic autoimmune disorder characterized by the lymphocytic infiltration of exocrine glands, particularly the salivary and lacrimal glands, which can lead to xerostomia and keratoconjunctivitis sicca [3-5]. In addition, SS may involve dryness and chronic inflammation of the sinonasal mucosa, which may cause CRS [3].

Min et al. reported systemic lupus erythematosus and rheumatoid arthritis as risk factors for CRS [6]. Lester et al. found a strong association between sicca symptoms and CRS [3]. SS is a major autoimmune disease, and patients with SS present typical sicca symptoms. Midilli et al. reported that among 77 patients with SS, two patients had sinusitis and among 77 healthy controls, one patient had sinusitis, without a statistically significant difference in either comparison [7]. Previous studies concerning the relationship between SS and CRS are scant, controversial, and lack long-term follow-up. To the best of our knowledge, the risk of CRS among patients with SS remains unknown. Therefore, in the present study, we investigated the effect of SS on the occurrence of CRS.

\section{Materials and Methods}

\subsection{National Health Insurance Research Database}

In March 1995, the Taiwanese government started the National Health Insurance Program, which currently covers $99.6 \%$ of Taiwan's population [8]. The National Health Insurance Research Database (NHIRD) is a de-identified database that contains all medical claims that are data generated during reimbursement for insurance in an electronic format, including disease diagnoses for clinic visits and hospitalization, prescription drugs and doses, examinations, procedures, surgeries, payments, residential locations, and income levels for all beneficiaries. The diagnosis sets consist of three codes for outpatient visits and five codes for hospitalization. These codes are based on the International Classification of Diseases, Ninth Revision, Clinical Modification (ICD-9-CM).

We conducted this study in accordance with the guidelines of the Declaration of Helsinki. This study was granted exemption from the need for obtaining informed consent from participants, because the data were de-identified. All information of insurants was safeguarded to ensure their anonymity, and this study did not violate their rights or adversely affect their welfare. This study was approved by the Institutional Review Board (IRB) of Chang Gung Memorial Hospital (IRB number 201701329B1). The datasets generated and/or analyzed during the current study are available in the Taiwan National Health Insurance Research Database repository.

\subsection{Study Group: Registry for Catastrophic Illness Patients}

In the Taiwan National Health Insurance system, the Registry for Catastrophic Illness Patients (RFCIP) was established to enable a particular group of patients to benefit from the treatment of relevant catastrophic illnesses. Based on the disease definition in the registry system established using NHIRD, SS is categorized as a catastrophic illness, and patients with SS can apply for a catastrophic illness certificate. A patient with catastrophic illness certification is eligible for a large medical expense discount. The certification process requires critical evaluation of patients' medical records, as well as serological and/or pathological reports by experts who are specialists in the disease field. Therefore, the diagnosis of enrolled patients with SS is highly accurate and reliable.

From the RFCIP, we identified all patients diagnosed with SS (ICD-9-CM code 710.2) between January 1997 and December 2011 as our study group. Patients diagnosed with SS before 1997 and those diagnosed with SS after 2012 were excluded to confirm that SS was newly diagnosed and to ensure a follow-up period of at least 2 years. Patients were followed up until death or the end of the study period (31 December, 2013). We excluded patients with a previous diagnosis of CRS before SS to ensure the validity of our results concerning SS as a predisposing factor for CRS. We also excluded patients with malignancies such as nasal/sinus/nasopharyngeal cancer (ICD-9-CM code $147 \times$ or $160 \times$ ), 
oral cancer (ICD-9-CM code $145 \times$ ), acquired immunodeficiency syndrome (AIDS; ICD-9-CM codes 042, 079.53, and 795.71), and cystic fibrosis (ICD-9-CM code $2770 \times$ ). Those diseases were thought to be triggers for CRS, which would confound the results of the study. After exclusion, 15,598 individuals with SS were enrolled into the study group (Figure 1). The date of enrolment was defined as the date of the initial diagnosis date of SS.

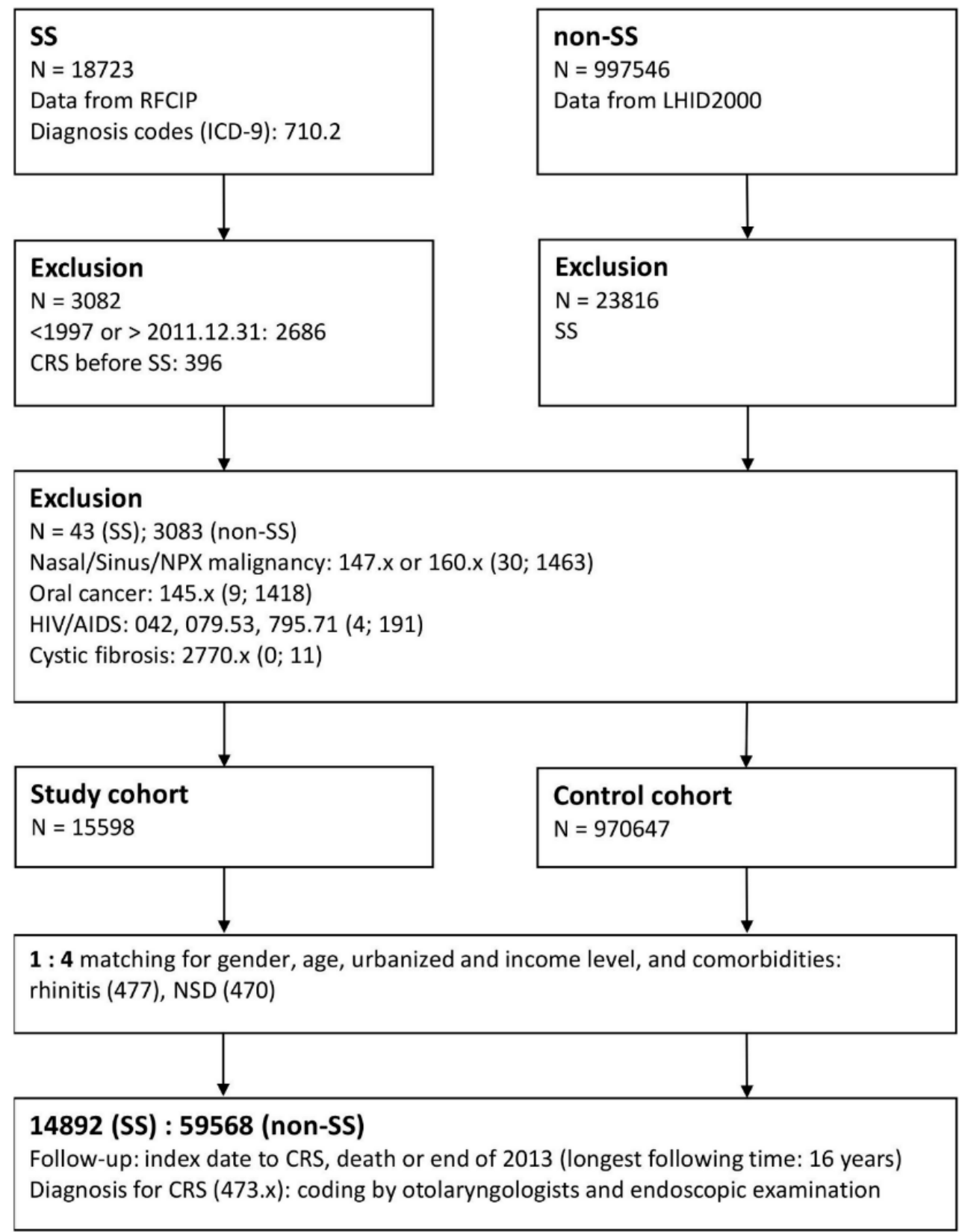

Figure 1. Enrollment flowchart of the study patients. Abbreviations: SS, Sjögren's syndrome; RFCIP, Registry for Catastrophic Illness Patients; LHID2000, Longitudinal Health Insurance Database 2000; CRS, chronic rhinosinusitis; NPX, nasopharynx; HIV, human immunodeficiency virus; AIDS, acquired immune deficiency syndrome; NSD, nasal septal deviation.

\subsection{Comparison Group: LHID2000 Database}

The Longitudinal Health Insurance Database 2000 (LHID2000) consists of the data of 1 million patients randomly selected from NHIRD in 2000. According to a report by the National Health Research Institutes, no statistically significant differences exist in age, sex, or healthcare costs between 
the LHID2000 sample group and all enrollees in the NHIRD, and the LHID2000 has been used in several population-based studies [9-11]. Therefore, we used the LHID2000 to enroll patients without SS into the comparison group. According to the same exclusion criteria for the SS group, individuals with nasal/sinus/nasopharyngeal cancer, oral cancer, AIDS, and cystic fibrosis were excluded on the basis of the defined ICD-9-CM codes. For the comparison group, the start of the follow-up was defined as the date of the first visit to a medical facility in the year of enrolment. Patients diagnosed with CRS before enrolment were excluded from this study.

\subsection{Matching Process}

For comparison purposes, four patients without SS from the LHID2000 were matched to one patient with SS by sex, age, urbanization level, income level, and comorbidities. Comorbidities were defined as rhinitis (ICD-9-CM code 477) and nasal septal deviation (NSD; ICD-9-CM code 470). After the matching process, the sample comprised 14,892 patients with SS and 59,568 patients without SS in the study and comparison groups, respectively.

\subsection{Main Outcome: Incidence of CRS}

The primary outcome was the occurrence of CRS (ICD-9-CM code 473), which is defined as a diagnosis of CRS in inpatient settings, and in outpatient settings, the CRS diagnosis should fulfil the two following conditions: certified by an otolaryngologist and one or more than one endoscopic examinations received [12].

\subsection{Comorbidities}

The comorbidities associated with CRS were retrieved from the claims data: rhinitis (ICD-9-CM code 477) [13,14], NSD (ICD-9-CM code 470), gastroesophageal reflux disease (GERD) (ICD-9-CM codes 530.11 and 530.81) [15], chronic obstructive pulmonary disease (COPD) (ICD-9-CM codes 491, 492, and 496), asthma (ICD-9-CM code 493) [16], diabetes mellitus (DM) (ICD-9-CM code 250), hypertension (HT) (ICD-9-CM codes 401-405) [17], systemic lupus erythematosus (SLE) (ICD-9-CM code 710.0) [9], and rheumatoid arthritis (RA) (ICD-9-CM code 714) [18]. The comorbidities were included if they occurred one or more times in inpatient records or three or more times in outpatient records. Comorbidities were included if they occurred from 12 months before enrolment to the end of the follow-up period.

\subsection{Analysis of CRS therapies}

We analyzed the associated treatment for CRS in the SS and comparison groups, including the dosage of intranasal corticosteroid spray (INCS) used and the surgical intervention. Sinus surgeries included endoscopic and open procedures such as sinusectomy, sinusotomy, polypectomy, and Caldwell Luc operation.

\subsection{Statistical Analysis}

The demographic characteristics and comorbidities of the SS and non-SS groups were compared using a Pearson's chi-squared test for categorical variables and an unpaired Student's $t$ test for continuous variables. Variables examined in univariate analysis that displayed a $p$ value less than 0.1 were included in multivariate analysis. Kaplan-Meier analysis was used to estimate the cumulative incidence of CRS, and the differences between two groups were determined using a two-tailed log-rank test. Multivariable Cox proportional hazard regression models were applied to measure the hazard ratio (HR) and 95\% confidence interval (CI) of CRS incidence in patients with SS in comparison with those of patients without SS. In addition, the stability of the effect of SS on CRS was examined through sensitivity and subgroup analyses. All analyses were performed using SAS software version 9.4 (SAS Institute, Cary, NC, USA), and the level of statistical significance was set at $p<0.05$. 


\section{Results}

Table 1 displays the baseline characteristics and comorbidities of the study and comparison groups. The SS group had a significantly higher prevalence of GERD, COPD, asthma, DM, SLE, and RA, but not of HT, than the non-SS group (Table 1). Among 14,892 patients with SS, 407 patients with CRS were identified in a mean follow-up period of $4.98 \pm 3.62$ years. By contrast, among 59,568 patients without SS, 667 patients with CRS were identified in a mean observation period of $5.2 \pm 3.53$ years. The incidence of CRS was significantly higher in the SS group than in the comparison group $(p<0.001)$.

Table 1. Baseline characteristics of study patients.

\begin{tabular}{|c|c|c|c|c|c|}
\hline \multirow{2}{*}{ Characteristics } & \multicolumn{2}{|c|}{ SS } & \multicolumn{2}{|c|}{ Non-SS } & \multirow{2}{*}{$p$-value * } \\
\hline & $n$ & $\%$ & $n$ & $\%$ & \\
\hline Total & 14,892 & & 59,568 & & \\
\hline Gender & & & & & 1 \\
\hline Male & 1551 & 10.4 & 6204 & 10.4 & \\
\hline Female & 13341 & 89.6 & 53,364 & 89.6 & \\
\hline Age (years) & & & & & 1 \\
\hline$<65$ & 11742 & 78.9 & 46,968 & 78.9 & \\
\hline$\geq 65$ & 3150 & 21.2 & 12,600 & 21.2 & \\
\hline Urbanized level & & & & & 1 \\
\hline 1 (City) & 4692 & 31.5 & 18,768 & 31.5 & \\
\hline 2 & 6571 & 44.1 & 26,284 & 44.1 & \\
\hline 3 & 2140 & 14.4 & 8560 & 14.4 & \\
\hline 4 (Village) & 1489 & 10.0 & 5956 & 10.0 & \\
\hline Income (NTD, per month) & & & & & 1 \\
\hline 0 & 3375 & 22.7 & 13,500 & 22.7 & \\
\hline $1-15,840$ & 2096 & 14.1 & 8384 & 14.1 & \\
\hline $15,841-25,000$ & 6390 & 42.9 & 25,560 & 42.9 & \\
\hline$\geq 25,001$ & 3031 & 20.4 & 12,124 & 20.4 & \\
\hline \multicolumn{6}{|l|}{ Comorbidities } \\
\hline Rhinitis & 5639 & 37.9 & 22,561 & 37.9 & 1 \\
\hline NSD & 136 & 0.9 & 544 & 0.9 & 1 \\
\hline GERD & 4378 & 29.4 & 8193 & 13.6 & $<0.001$ \\
\hline COPD & 2877 & 19.3 & 7605 & 12.8 & $<0.001$ \\
\hline Asthma & 2230 & 15.0 & 7086 & 11.9 & $<0.001$ \\
\hline DM & 2411 & 16.2 & 11,787 & 19.8 & $<0.001$ \\
\hline $\mathrm{HT}$ & 5837 & 39.2 & 23,690 & 39.8 & 0.200 \\
\hline SLE & 3156 & 21.2 & 183 & 0.3 & $<0.001$ \\
\hline RA & 4299 & 28.9 & 1618 & 2.7 & $<0.001$ \\
\hline \multicolumn{6}{|l|}{ CRS } \\
\hline Total & 408 & 2.7 & 667 & 1.1 & $<0.001$ \\
\hline
\end{tabular}

Abbreviations: SS, Sjögren's syndrome; NTD, New Taiwan dollar; NSD, nasal septal deviation; GERD, gastroesophageal reflux disease; COPD, chronic obstructive pulmonary disease; DM, diabetes mellitus; HT, hypertension; SLE, systemic lupus erythematosus; RA, rheumatoid arthritis; CRS, chronic rhinosinusitis; * Statistical significance was expressed by $p$ value $<0.05$.

The Kaplan-Meier method was used to estimate the cumulative incidence of CRS in both groups. The results indicated that the SS group had a significantly higher incidence of CRS than the non-SS group $(p<0.001)$ (Figure 2). The Cox proportional hazard model was used to estimate crude and adjusted HRs for both groups after adjustment for sex, age, urbanization level, income level, and the selected comorbidities, which were found to be significantly different in univariate analysis. The risk of CRS in patients with SS was 2.51-fold higher than that in patients without SS (adjusted HR, 2.51; 95\% CI, 2.22-2.84; $p<0.001$ ) (main model in Table 2). In addition, sensitivity analysis revealed a considerable stabilizing effect of SS on CRS occurrence. Subgroup analysis revealed that the effect of SS remained significant in the subgroup analysis for GERD, COPD, asthma, DM, HT, and RA. 


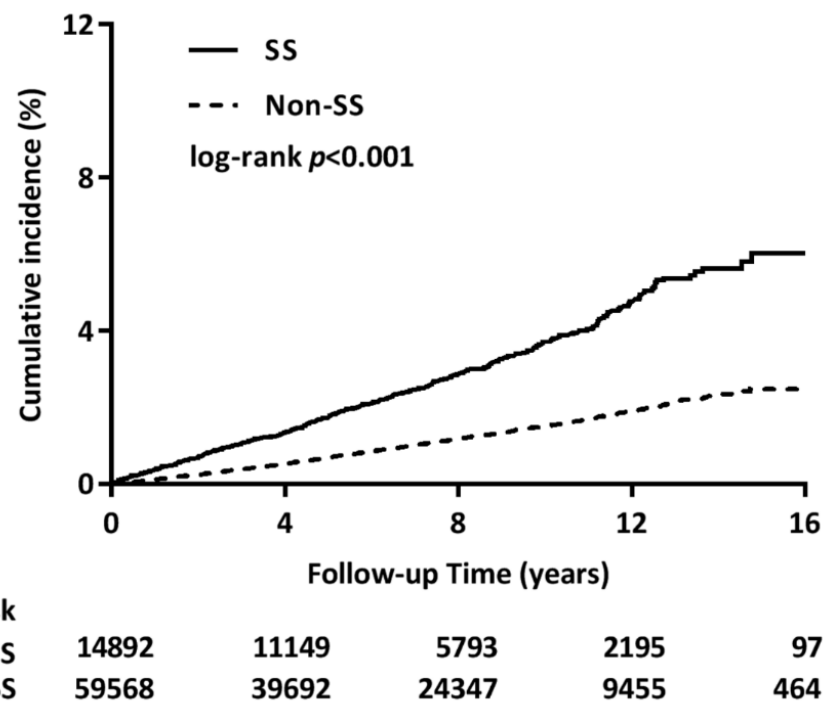

Figure 2. Cumulative incidence of CRS in patients with and without SS. SS, Sjögren's syndrome. Patients with SS had a significantly higher cumulative incidence of chronic rhinosinusitis than those without SS.

Table 2. Multivariable cox proportional hazard model of association between chronic rhinosinusitis and Sjögren's syndrome.

\begin{tabular}{|c|c|c|c|}
\hline Variables & HR & $95 \%$ CI & $p$-value \\
\hline Main model $*$ & 2.51 & $(2.22-2.84)$ & $<0.001$ \\
\hline \multicolumn{4}{|l|}{ Additional covariates ${ }^{\dagger}$} \\
\hline Main model+GERD & 2.52 & $(2.22-2.86)$ & $<0.001$ \\
\hline Main model+COPD & 2.51 & $(2.22-2.84)$ & $<0.001$ \\
\hline Main model+Asthma & 2.51 & $(2.22-2.84)$ & $<0.001$ \\
\hline Main model+DM & 2.48 & $(2.20-2.81)$ & $<0.001$ \\
\hline Main model+HT & 2.50 & $(2.21-2.83)$ & $<0.001$ \\
\hline Main model+SLE & 2.57 & $(2.25-2.94)$ & $<0.001$ \\
\hline Main model+RA & 2.69 & $(2.36-3.08)$ & $<0.001$ \\
\hline \multicolumn{4}{|l|}{ Subgroup effects } \\
\hline \multicolumn{4}{|l|}{ GERD } \\
\hline Yes & 2.21 & $(1.73-2.83)$ & $<0.001$ \\
\hline No & 2.64 & $(2.28-3.05)$ & $<0.001$ \\
\hline \multicolumn{4}{|l|}{ COPD } \\
\hline Yes & 2.16 & $(1.66-2.82)$ & $<0.001$ \\
\hline No & 2.60 & $(2.26-2.99)$ & $<0.001$ \\
\hline \multicolumn{4}{|l|}{ Asthma } \\
\hline Yes & 2.18 & $(1.63-2.90)$ & $<0.001$ \\
\hline No & 2.58 & $(2.25-2.96)$ & $<0.001$ \\
\hline \multicolumn{4}{|l|}{$\mathrm{DM}$} \\
\hline Yes & 2.71 & $(1.99-3.68)$ & $<0.001$ \\
\hline No & 2.47 & $(2.15-2.82)$ & $<0.001$ \\
\hline \multicolumn{4}{|l|}{ HT } \\
\hline Yes & 2.74 & $(2.25-3.33)$ & $<0.001$ \\
\hline No & 2.35 & $(2.01-2.76)$ & $<0.001$ \\
\hline \multicolumn{4}{|l|}{ SLE } \\
\hline Yes & 4.71 & $(0.65-33.9)$ & 0.124 \\
\hline No & 2.56 & $(2.24-2.92)$ & $<0.001$ \\
\hline \multicolumn{4}{|l|}{ RA } \\
\hline Yes & 2.25 & $(1.38-3.68)$ & 0.001 \\
\hline No & 2.71 & $(2.36-3.11)$ & $<0.001$ \\
\hline
\end{tabular}

Abbreviations: HR, hazard ratio; CI, confidence interval; Abbreviations: SS, Sjögren's syndrome; NTD, New Taiwan dollar; NSD, nasal septal deviation; GERD, gastroesophageal reflux disease; COPD, chronic obstructive pulmonary disease; DM, diabetes mellitus; HT, hypertension; SLE, systemic lupus erythematosus; RA, rheumatoid arthritis; CRS, chronic rhinosinusitis. * Main model is stratified by sex, age, urbanization, income, rhinitis, and nasal septal deviation. ${ }^{+}$The models are adjusted for covariates in the main model, as well as each additional listed covariate. 
Table 3 shows the associated therapies for CRS in the two groups. The dosage of INCS used was not significantly different between the SS and non-SS groups, regardless of whether vials or doses were counted. More patients received sinus surgery in the non-SS group than in the SS group (SS vs. non-SS, $82 / 407(20.2 \%)$ vs. $179 / 667(26.84 \%) ; p=0.013)$. No difference was observed in the number of surgical interventions between the two groups (number of surgeries received per patient, SS vs. non-SS, $1.07 \pm 0.19$ vs. $1.14 \pm 0.31 ; p=0.064)$.

Table 3. Analysis of Medical and Surgical Therapies for CRS in SS and Non-SS.

\begin{tabular}{cccc}
\hline & SS-CRS & Non-SS-CRS & \\
\hline Characteristic & $n=407$ & $n=667$ & $p$-value * \\
\hline INCS (mean \pm SD) & & & \\
vial, per year & $1.42 \pm 1.71$ & $1.50 \pm 3.39$ & 0.712 \\
mg, per year & $11.43 \pm 18.36$ & $13.02 \pm 34.87$ & 0.491 \\
Surgery & & & \\
Yes or No & $82(20.2 \%)$ & $179(26.84 \%)$ & 0.013 \\
times (mean \pm SD) & $1.07 \pm 0.19$ & $1.14 \pm 0.31$ & 0.064
\end{tabular}

* Abbreviations: CRS, chronic rhinosinusitis; SS, Sjögren's syndrome; INCS, intranasal corticosteroid spray; SD, standard deviation.

\section{Discussion}

Researchers have provided controversial conclusions regarding the predisposition of patients with SS toward CRS, and studies evaluating the relationship between SS and CRS are scant $[3,7]$. To the best of our knowledge, this is the first population-based study with long-term follow-up to investigate the risk of CRS in patients with SS. This study indicated that SS is a definite risk factor for sinusitis development, with a 2.5 -fold risk.

SS is a systemic autoimmune disease and can thus affect exocrine glands, particularly the lacrimal and salivary glands, which can lead to the poor clearance of chronic inflammatory infiltrates [3]. Researchers have reported that SS can increase the risks of inflammation and infection in the lower respiratory tract. Nearly one-fourth of patients with SS have interstitial lung disease, and they also have potential risks of interstitial pneumonia, pleural disease, and community-acquired pneumonia [19-22]. However, SS might involve not only the lower airway but also the upper aerodigestive tract. Decreased secretion in the sinonasal tract may cause mucociliary function impairment, which may cause a thicker mucus layer with higher viscosity to be secreted and prolong mucociliary transport time [23]. Furthermore, SS may decrease the innate immune content concentration in the exocrine glands [24]. Decreased amylase and carbonic anhydrase in the secretion might impair innate immunity, which functions as a natural barrier $[25,26]$. SS also affects Meibomian glands, resulting in the increased evaporation of tears $[27,28]$. Without the moisture of natural tears from the nasolacrimal duct, the sinonasal cavity becomes drier, thus increasing the viscosity of mucus [29]. SS can lead to more frequent local inflammation and infection in the upper airway, as well as to small airway disease due to poor sputum clearance in the lower respiratory tract [30-32]. The aforementioned complications may explain our finding that $\mathrm{SS}$ is as a risk factor for CRS.

For CRS, saline nasal irrigation and INCS may be recommended as mainstay therapies. If medical treatment fails, surgical intervention should be considered [33-35]. In our study, SS patients with CRS did not use a higher amount of INCS than non-SS patients with CRS however, more patients received sinus surgery in the non-SS group than in the SS group, although the number of operations received per patient was not significantly higher. Because patients having CRS without nasal polyposis (CRSsNP) present with facial pain, pressure, and fullness more often than those having CRS with nasal polyposis (CRSwNP), which is frequently characterized by hyposmia and obstruction signs [36,37], patients with CRSwNP are more willing to accept sinus surgery to solve the annoying stuffiness affecting their breathing [37-40]. In Western countries, nearly $80 \%$ of individuals with CRSwNP are characterized by T-helper type 2 cell (Th2) cytokine expression, high tissue eosinophilia, frequent epithelial damage, 
a thickened basement membrane, and mostly edematous to sometimes fibrotic stromal tissue [41-43], which was thought to represent an inflammatory aetiology. By contrast, T-helper type 1 cell (Th1) cytokine expression is elevated in patients with CRSsNP compared with those with CRSwNP, with less eosinophilic infiltration [41,43], and infection is considered to be the main aetiology. Lin et al. reported GERD as a risk factor for CRS, and in their study, individuals with GERD and CRS had a higher incidence of CRSsNP (CRSsNP vs. CRSwNP, 48.80 vs. 19.59 persons per 10,000 person-years) [12]. Furthermore, Wong et al. reported that gastroesophageal reflux may stimulate the vagus nerve to cause a vagally mediated neural reflux between the esophagus and paranasal sinuses [44]. Other studies have also reported that the vagally mediated laryngotracheal reflux may trigger overproduction of mucus in the sinonasal tract and lead to sinus infections $[45,46]$. Therefore, considering the aforementioned information, we hypothesized that SS would be an infection-dominant aetiology for CRS, and that CRS might tend to be CRSsNP, which explains fewer surgical interventions in the SS CRS group than in the non-SS CRS group in our study. Further prospective study is needed to confirm our hypothesis.

Our study has several strengths. First, it was conducted using the RFCIP, which is affiliated with the NHIRD, and provides data of patients with accurate and reliable diagnosis of SS. Second, confirmation of CRS depends not only on ICD-9 codes but also on endoscopic examination and diagnosis specifically by otolaryngologists in the claims data. Third, our study included a large number of patients and conducted long follow-up, allowing us to present a nationwide overview.

Our study has some limitations. Patients with SS were identified using ICD codes instead of case collection. Therefore, in this study, information on clinical presentation and therapeutic course, laboratory data, radiological findings, and surgical and pathology reports were lacking, which are needed to investigate SS disease severity of and types of sinusitis (CRSsNP or CRSwNP).

\section{Conclusions}

To the best of our knowledge, our study is the first to verify SS as a definite risk factor for CRS within a five year follow-up period on average, with a 2.5-fold risk. Our study extends the SS disease spectrum and reminds physicians to be aware of potential CRS occurrence in patients with SS. Further research should be conducted to explore the characteristics of SS-CRS, methods to prevent CRS development, and improve treatment.

Author Contributions: Conceptualization, G.-H.C. and M.-S.T.; Methodology, Y.-C.C. and Y.-H.Y.; Software, C.-Y.L. and M.-H.L.; Validation, K.-M.L., C.-Y.W. and C.-M.H.; Formal Analysis, C.-Y.L.; Investigation, G.-H.C. and M.-S.T.; Resources, C.-Y.W. and C.-M.H.; Writing-Original Draft Preparation, G.-H.C. and Y.-C.C.; Writing-Review \& Editing, M.-S.T.; Supervision, Y.-H.Y. and M.-S.T.

Funding: The article did not have any financial support provided by companies toward the completion of the work.

Acknowledgments: The authors would like to thank Health Information and Epidemiology Laboratory (CLRPG6G0041), Chang Gung Memorial Hospital, Chiayi Branch, for the comments and assistance in data analysis. This study was supported by a grant from Chang Gung Memorial Hospital, Chiayi Branch (CGRPG6G0011), and was based on the National Health Insurance Research Database provided by the Central Bureau of National Health Insurance, the Department of Health, and managed by the National Health Research Institutes. The interpretation and conclusions contained herein do not represent those of Bureau of National Health Insurance, Department of Health, or National Health Research Institutes.

Conflicts of Interest: The authors declare no conflict of interest. 


\section{List of abbreviations}

$\begin{array}{ll}\text { GERD } & \text { gastroesophageal reflux disease } \\ \text { CI } & \text { confidence interval } \\ \text { CIP } & \text { Catastrophic Illness Patients } \\ \text { COPD } & \text { chronic obstructive pulmonary disease } \\ \text { CRS } & \text { chronic rhinosinusitis } \\ \text { CRSsNP } & \text { chronic rhinosinusitis without nasal polyposis } \\ \text { CRSwNP } & \text { chronic rhinosinusitis with nasal polyposis } \\ \text { DM } & \text { diabetes mellitus } \\ \text { HT } & \text { hypertension } \\ \text { HR } & \text { hazard ratio } \\ \text { ICD-9-CM } & \text { International Classification of Diseases, Ninth Revision, Clinical Modification } \\ \text { LHID2000 } & \text { Longitudinal Health Insurance Database 2000 } \\ \text { NHIRD } & \text { National Health Insurance Research Database } \\ \text { NSD } & \text { nasal septal deviation } \\ \text { RA } & \text { rheumatic arthritis } \\ \text { RFCIP } & \text { Registry for Catastrophic Illness Patients } \\ \text { SLE } & \text { systemic lupus erythematosus }\end{array}$

\section{References}

1. Rudmik, L.; Smith, T.L. Quality of Life in Patients with Chronic Rhinosinusitis. Curr. Allergy Asthma Rep. 2011, 11, 247-252. [CrossRef] [PubMed]

2. Halawi, A.M.; Smith, S.S.; Chandra, R.K. Chronic Rhinosinusitis: Epidemiology and Cost. Allergy Asthma Proc. 2013, 34, 328-334. [CrossRef] [PubMed]

3. Lester, S.; Rischmueller, M.; Tan, L.; Wormald, P.; Zalewski, P.; Hamilton-Bruce, M.; Appleton, S.; Adams, R.; Hill, C. Sicca Symptoms and Their Association with Chronic Rhinosinusitis in a Community Sample. Open Rheumatol. J. 2012, 6, 170-174. [CrossRef]

4. Reksten, T.R.; Jonsson, M.V. Sjogren's Syndrome: An Update on Epidemiology and Current Insights on Pathophysiology. Oral Maxillofac. Surg. Clin. N. Am. 2014, 26, 1-12. [CrossRef] [PubMed]

5. Price, E.J.; Venables, P.J. Dry Eyes and Mouth Syndrome-A Subgroup of Patients Presenting with Sicca Symptoms. Rheumatology (Oxf.) 2002, 41, 416-422. [CrossRef]

6. Min, J.Y.; Tan, B.K. Risk Factors for Chronic Rhinosinusitis. Curr. Opin. Allergy Clin. Immunol. 2015, 15, 1-13. [CrossRef]

7. Midilli, R.; Gode, S.; Oder, G.; Kabasakal, Y.; Karci, B. Nasal and Paranasal Involvement in Primary Sjogren's Syndrome. Rhinology 2013, 51, 265-267. [CrossRef] [PubMed]

8. Tsai, M.S.; Lee, L.A.; Tsai, Y.T.; Yang, Y.H.; Liu, C.Y.; Lin, M.H.; Hsu, C.M.; Chen, C.K.; Li, H.Y. Sleep Apnea and Risk of Vertigo: A Nationwide Population-Based Cohort Study. Laryngoscope 2018, 128, 763-768. [CrossRef]

9. Chang, G.H.; Tsai, M.S.; Liu, C.Y.; Lin, M.H.; Tsai, Y.T.; Hsu, C.M.; Yang, Y.H. End-Stage Renal Disease: A Risk Factor of Deep Neck Infection-A Nationwide Follow-up Study in Taiwan. BMC Infect. Dis. 2017, 17, 424. [CrossRef]

10. Tsai, M.S.; Yang, Y.H.; Liu, C.Y.; Lin, M.H.; Chang, G.H.; Tsai, Y.T.; Li, H.Y.; Tsai, Y.H.; Hsu, C.M. Unilateral Vocal Fold Paralysis and Risk of Pneumonia: A Nationwide Population-Based Cohort Study. Otolaryngol. Head Neck Surg. 2018, 158, 896-903. [CrossRef]

11. Tsai, M.S.; Lin, M.H.; Lee, C.P.; Yang, Y.H.; Chen, W.C.; Chang, G.H.; Tsai, Y.T.; Chen, P.C.; Tsai, Y.H. Chang Gung Research Database: A Multi-Institutional Database Consisting of Original Medical Records. Biomed. J. 2017, 40, 263-269. [CrossRef] [PubMed]

12. Lin, Y.H.; Chang, T.S.; Yao, Y.C.; Li, Y.C. Increased Risk of Chronic Sinusitis in Adults with Gastroesophgeal Reflux Disease: A Nationwide Population-Based Cohort Study. Medicine (Baltim.) 2015, 94, e1642. [CrossRef] [PubMed] 
13. Huang, S.K.; Ho, Y.L.; Chang, Y.S. Prescriptions of Traditional Chinese Medicine, Western Medicine, and Integrated Chinese-Western Medicine for Allergic Rhinitis under the National Health Insurance in Taiwan. J. Ethnopharmacol. 2015, 173, 212-216. [CrossRef] [PubMed]

14. Siao, M.J.; Chen, G.S.; Lee, W.C.; Horng, J.T.; Chang, C.W.; Li, C.H. Increased Risk of Dental Trauma in Patients with Allergic Rhinitis: A Nationwide Population-Based Cohort Study. PLoS ONE 2017, 12, e0182370. [CrossRef] [PubMed]

15. Chuang, Y.W.; Yu, M.C.; Lin, C.L.; Yu, T.M.; Shu, K.H.; Kao, C.H. Risk of Peripheral Arterial Occlusive Disease in Patients with Systemic Lupus Erythematosus: A Nationwide Population-Based Cohort Study. Medicine (Baltim.) 2015, 94, e2121. [CrossRef] [PubMed]

16. Kuo, C.-L.; Yen, Y.-C.; Chang, W.-P.; Shiao, A.-S. Association between Middle Ear Cholesteatoma and Chronic Rhinosinusitis. JAMA Otolaryngol. Head Neck Surg. 2017, 143, 757-763. [CrossRef] [PubMed]

17. Tsai, Y.T.; Huang, E.I.; Chang, G.H.; Tsai, M.S.; Hsu, C.M.; Yang, Y.H.; Lin, M.H.; Liu, C.Y.; Li, H.Y. Risk of Acute Epiglottitis in Patients with Preexisting Diabetes Mellitus: A Population-Based Case-Control Study. PLoS ONE 2018, 13, e0199036. [CrossRef]

18. Puri, V.; Khare, N.A.; Chandramouli, M.V.; Shende, N.; Bharadwaj, S. Comparative Analysis of Early Excision and Grafting Vs Delayed Grafting in Burn Patients in a Developing Country. J. Burn Care Res. 2016, 37, 278-282. [CrossRef]

19. Bouros, D.; Pneumatikos, I.; Tzouvelekis, A. Pleural Involvement in Systemic Autoimmune Disorders. Respiration 2008, 75, 361-371. [CrossRef]

20. Ito, I.; Nagai, S.; Kitaichi, M.; Nicholson, A.G.; Johkoh, T.; Noma, S.; Kim, D.S.; Handa, T.; Izumi, T.; Mishima, M. Pulmonary Manifestations of Primary Sjogren's Syndrome: A Clinical, Radiologic, and Pathologic Study. Am. J. Respir. Crit. Care Med. 2005, 171, 632-638. [CrossRef]

21. Parambil, J.G.; Myers, J.L.; Lindell, R.M.; Matteson, E.L.; Ryu, J.H. Interstitial Lung Disease in Primary Sjogren Syndrome. Chest 2006, 130, 1489-1495. [CrossRef] [PubMed]

22. Castelino, F.V.; Varga, J. Interstitial Lung Disease in Connective Tissue Diseases: Evolving Concepts of Pathogenesis and Management. Arthritis Res. Ther. 2010, 12, 213. [CrossRef] [PubMed]

23. Takeuchi, K.; Sakakura, Y.; Murai, S.; Majima, Y. Nasal Mucociliary Clearance in Sjogren's Syndrome. Dissociation in Flow between Sol and Gel Layers. Acta Otolaryngol. 1989, 108, 126-129. [CrossRef] [PubMed]

24. Hu, S.; Wang, J.; Meijer, J.; Ieong, S.; Xie, Y.; Yu, T.; Zhou, H.; Henry, S.; Vissink, A.; Pijpe, J.; et al. Salivary Proteomic and Genomic Biomarkers for Primary Sjogren's Syndrome. Arthritis Rheum. 2007, 56, 3588-3600. [CrossRef] [PubMed]

25. Fabian, T.K.; Hermann, P.; Beck, A.; Fejerdy, P.; Fabian, G. Salivary Defense Proteins: Their Network and Role in Innate and Acquired Oral Immunity. Int. J. Mol. Sci. 2012, 13, 4295-4320. [CrossRef] [PubMed]

26. Hains, D.S.; Chen, X.; Saxena, V.; Barr-Beare, E.; Flemming, W.; Easterling, R.; Becknell, B.; Schwartz, G.J.; Schwaderer, A.L. Carbonic Anhydrase 2 Deficiency Leads to Increased Pyelonephritis Susceptibility. Am. J. Physiol. Ren. Physiol. 2014, 307, F869-F880. [CrossRef] [PubMed]

27. Goto, E.; Matsumoto, Y.; Kamoi, M.; Endo, K.; Ishida, R.; Dogru, M.; Kaido, M.; Kojima, T.; Tsubota, K. Tear Evaporation Rates in Sjogren Syndrome and Non-Sjogren Dry Eye Patients. Am. J. Ophthalmol. 2007, 144, 81-85. [CrossRef]

28. Shimazaki, J.; Goto, E.; Ono, M.; Shimmura, S.; Tsubota, K. Meibomian Gland Dysfunction in Patients with Sjogren Syndrome. Ophthalmology 1998, 105, 1485-1488. [CrossRef]

29. Absolon, M.J.; Brown, C.A. Acetylcysteine in Kerato-Conjunctivitis Sicca. Br. J. Ophthalmol. 1968, 52, 310-316. [CrossRef]

30. Lopez-Pintor, R.M.; Castro, M.F.; Hernandez, G. Oral Involvement in Patients with Primary Sjogren's Syndrome. Multidisciplinary Care by Dentists and Rheumatologists. Reumatol. Clin. 2015, 11, 387-394. [CrossRef]

31. Leung, K.C.; McMillan, A.S.; Cheung, B.P.; Leung, W.K. Sjogren's Syndrome Sufferers Have Increased Oral Yeast Levels Despite Regular Dental Care. Oral Dis. 2008, 14, 163-173. [CrossRef] [PubMed]

32. Cojocaru, M.; Cojocaru, I.M.; Silosi, I.; Vrabie, C.D. Pulmonary Manifestations of Systemic Autoimmune Diseases. Maedica (Buchar) 2011, 6, 224-229. [PubMed]

33. Rosenfeld, R.M.; Andes, D.; Bhattacharyya, N.; Cheung, D.; Eisenberg, S.; Ganiats, T.G.; Gelzer, A.; Hamilos, D.; Haydon, R.C., 3rd; Hudgins, P.A.; et al. Clinical Practice Guideline: Adult Sinusitis. Otolaryngol. Head Neck Surg. 2007, 137, S1-S31. [CrossRef] [PubMed] 
34. Rosenfeld, R.M.; Piccirillo, J.F.; Chandrasekhar, S.S.; Brook, I.; Kumar, K.A.; Kramper, M.; Orlandi, R.R.; Palmer, J.N.; Patel, Z.M.; Peters, A.; et al. Clinical Practice Guideline (Update): Adult Sinusitis. Otolaryngol. Head Neck Surg. 2015, 152, S1-S39. [CrossRef] [PubMed]

35. Kaplan, A. Canadian Guidelines for Chronic Rhinosinusitis: Clinical Summary. Can. Fam. Physician 2013, 59, 1275-1281. [PubMed]

36. Bachert, C.; Pawankar, R.; Zhang, L.; Bunnag, C.; Fokkens, W.J.; Hamilos, D.L.; Jirapongsananuruk, O.; Kern, R.; Meltzer, E.O.; Mullol, J.; et al. Icon: Chronic Rhinosinusitis. World Allergy Organ. J. 2014, 7, 25. [CrossRef] [PubMed]

37. Nair, S.; Dutta, A.; Rajagopalan, R.; Nambiar, S. Endoscopic Sinus Surgery in Chronic Rhinosinusitis and Nasal Polyposis: A Comparative Study. Indian J. Otolaryngol. Head Neck Surg. 2011, 63, 50-55. [CrossRef] [PubMed]

38. Li, Y.; Zhang, G.H.; Liu, X.; Ye, J.; Zeng, Z.P. Clinical Prognostic Factors of Chronic Rhinosinusitis after Endoscopic Sinus Surgery. ORL J. Otorhinolaryngol. Relat. Spec. 2008, 70, 113-117. [CrossRef] [PubMed]

39. Khalil, H.S.; Nunez, D.A. Functional Endoscopic Sinus Surgery for Chronic Rhinosinusitis. Cochrane Database Syst. Rev. 2006, CD004458. [CrossRef] [PubMed]

40. Gosepath, J.; Pogodsky, T.; Mann, W.J. Characteristics of Recurrent Chronic Rhinosinusitis after Previous Surgical Therapy. Acta Otolaryngol. 2008, 128, 778-784. [CrossRef] [PubMed]

41. Chaaban, M.R.; Walsh, E.M.; Woodworth, B.A. Epidemiology and Differential Diagnosis of Nasal Polyps. Am. J. Rhinol. Allergy 2013, 27, 473-478. [CrossRef] [PubMed]

42. Lee, S.H. Mechanisms of Glucocorticoid Action in Chronic Rhinosinusitis. Allergy Asthma Immunol. Res. 2015, 7, 534-537. [CrossRef] [PubMed]

43. Van Crombruggen, K.; Zhang, N.; Gevaert, P.; Tomassen, P.; Bachert, C. Pathogenesis of Chronic Rhinosinusitis: Inflammation. J. Allergy Clin. Immunol. 2011, 128, 728-732. [CrossRef] [PubMed]

44. Wong, I.W.; Rees, G.; Greiff, L.; Myers, J.C.; Jamieson, G.G.; Wormald, P.-J. Gastroesophageal Reflux Disease and Chronic Sinusitis: In Search of an Esophageal-Nasal Reflex. Am. J. Rhinol. Allergy 2010, 24, 255-259. [CrossRef] [PubMed]

45. Schan, C.A.; Harding, S.M.; Haile, J.M.; Bradley, L.A.; Richter, J.E. Gastroesophageal Reflux-Induced Bronchoconstriction: An Intraesophageal Acid Infusion Study Using State-of-the-Art Technology. Chest 1994, 106, 731-737. [CrossRef] [PubMed]

46. Wu, D.-N.; Tanifuji, Y.; Kobayashi, H.; Yamauchi, K.; Kato, C.; Suzuki, K.; Inoue, H. Effects of Esophageal Acid Perfusion on Airway Hyperresponsiveness in Patients with Bronchial Asthma. Chest 2000, 118, 1553-1556. [CrossRef] [PubMed]

(C) 2019 by the authors. Licensee MDPI, Basel, Switzerland. This article is an open access article distributed under the terms and conditions of the Creative Commons Attribution (CC BY) license (http://creativecommons.org/licenses/by/4.0/). 